\title{
ПУТИ СОВЕРШЕНСТВОВАНИЯ СИСТЕМЫ ОХЛАЖДЕНИЯ ДВИГАТЕЛЕЙ ЛЕГКОВЫХ АВТОМОБИЛЕЙ
}

\author{
В.П. Дмитренко (фото) \\ к.т.н., доцент кафедры технического сервиса \\ И.М. Соцкая \\ к.Т.н., доцент, заведующая кафедрой технического сервиса \\ Р.Д. Адакин \\ старший преподаватель кафедры технического сервиса \\ ФГБОУ ВО Ярославская ГСХА, г. Ярославль
}

На легковые автомобили и лёгкие грузовики в большинстве слу-

Легковой автомобиль, предпусковой прогрев, подогреватель, аккумулятор тепла, теплообменник масла

Motor car, prestart warming-up, heater, heat accumulator, oil heat exchanger чаев устанавливают двигатели с искровым воспламенением (бензиновые двигатели). В последние годы основным способом улучшения топливной экономичности и снижения выбросов вредных веществ является газотурбинный наддув (ТН). Если ТН для дизелей стал обязательным, то есть дизели без ТН вообще не выпускаются, то часть бензиновых двигателей продолжает выпускаться без него, но это является скорее исключением.

У двигателей с ТН тепловые и механические нагрузки растут примерно пропорционально росту мощности. Поэтому тепловые нагрузки у современных двигателей также значительно возросли. Следует напомнить, что из общего количества тепла, выделяемого при сгорании топлива, потери тепла в систему охлаждения составляют примерно 25-27\% (для бензиновых двигателей) и 18-20\% (для дизелей грузовых автомобилей).

Принятые стандартами нормы на допустимые выбросы веществ настолько жёсткие, что производители техники вынуждены внедрять целый комплекс сложных изменений и дополнительных систем, чтобы обеспечить эти требования. Помимо жёстких норм меняются и методы испытаний. Если, например, при контрольных испытаниях легковых автомобилей на стенде требованиями Евро-2 разрешалось до начала цикла испытаний прогреть двигатель в течение 40 секунд, то в настоящее время прогрев запрещён, и фиксация выбросов начинается сразу же после запуска двигателя. Кроме того, сейчас это в основном переменные режимы [1].

Рассматривая проблемы холодного пуска двигателей, специалисты основное внимание уделяют таким характеристикам, как минимальные пусковые обороты, стабильность воспламенения топлива, поддержание постоянной частоты вращения вала после пуска и другим, связанным, прежде всего, с облегчением пуска. Вопросы выбросов вредных веществ остаются второстепенными. 
При работе двигателя в режиме прогрева выбросы углеводородов $(\mathrm{CH})$ и моноксида углерода (СО) значительно превышают величины, фиксируемые при работе полностью прогретого двигателя на тех же режимах.

Если после длительной стоянки при температуре окружающего воздуха $+20^{\circ} \mathrm{C}$ водитель легкового автомобиля запускает двигатель, то время, в течение которого температура охлаждающей жидкости двигателя поднимется до $+85 \ldots+90^{\circ} \mathrm{C}$, составит 6-8 минут. Это при условии, что автомобиль будет двигаться с небольшой скоростью, при которой частота вращения коленвала будет примерно в 1,5 раза превышать минимальные обороты холостого хода. Увеличивать частоту вращения вала двигателя в режиме прогрева не рекомендуется из-за срабатывания перепускного клапана масляного фильтра. В этом случае в масляную магистраль пойдет нефильтрованное масло.

При низких температурах время прогрева существенно растёт, растут и выбросы СН. Например, у автомобиля среднего класса непосредственно после пуска при температуре окружающего воздуха $15^{\circ} \mathrm{C}$ концентрация в отработавших газах СН составляет 1000 ppm. Автомобиль сразу же после пуска начинает движение с небольшой скоростью. Прогрев двигателя при движении автомобиля более интенсивный, чем при работе на холостом ходу. Через 2,5 минуты движения концентрация СН снижается до 400 рpm, через 5 минут - до 200 ppm, через 7,5 минут - до 40 ppm и через 10 минут - до 20 рpm.

Специалисты указывают, что при неполном сгорании топлива в условиях низких температур образуется более 150 различных компонентов углеводородов. Наиболее опасны альдегиды это фомальдегид, акролеин и уксусный альдегид. Формальдегид поражает центральную нервную систему человека. Некоторые из углеводородов являются канцерогенами. Кроме того, углеводороды в атмосфере под действием солнечного ультрафиолетового излучения вступают в реакцию с оксидами азота и образуют биологически активные токсичные фотооксиданты, которые ведут к росту лёгочных заболеваний.

В США стандарты на выбросы автомобилями вредных веществ нормируют содержание формальдегида, но углеводороды метановой группы не считаются токсичными. В Европе нормируют общее количество углеводородов, но за последние годы несколько раз пересматривались нормативы на предельно допустимые концентрации в атмосфере углеводородов с целью их ужесточения.

Специальные исследования показывают, что формальдегид, бенз(а)пирен и другие полиароматические углеводороды, а также летучие органические углеводороды в атмосфере городов оказывают на человека вредное воздействие на один-три порядка более опасное, чем воздействие суммарных углеводородов, нормируемых стандартами. Среднегодовая концентрация перечисленных углеводородов в атмосфере 26 городов России в течение последних 10 лет почти в 10 раз превышает предельно допустимые концентрации [2].

Повышенные выбросы СН и СО происходят также при условиях, когда снижается максимальная температура сгорания. Это может быть при низких температурах окружающего воздуха, длительной работе двигателя на холостом ходу или на частичных нагрузках, при использовании в автомобиле системы Stop-and-Go, то есть в тех случаях, когда температура поверхностей камеры сгорания ниже значений фиксируемых при работе двигателя на режимах близких к номинальному. Но из общего количества выбрасываемых $\mathrm{CH}$ и СО большая часть приходится на режимы прогрева двигателя. Проблема усугубляется тем, что каталитический нейтрализатор начинает работать, когда температура отработавших газов превысит $250 \ldots 300^{\circ} \mathrm{C}$.

Кроме того, прогрев двигателя идёт при повышенных расходах топлива. Даже если в двигатель залито маловязкое загущенное масло, кинематическая вязкость которого при $100^{\circ} \mathrm{C} 5 \ldots 7$ $\mathrm{Mm}^{2} / \mathrm{C}$, то при температуре $20^{\circ} \mathrm{C}$ вязкость его около $50 \mathrm{~mm}^{2} /$ с. Силы вязкого трения пар скольжения пропорциональны вязкости масла. Потери, связанные с вязким трением в основном пар кольца, поршни - гильзы, даже на полностью прогретом двигателе составляют более половины от общих механических потерь в двигателе. Например, если при оборотах холостого хода 1200 мин $^{-1}$ полностью прогретого бензинового двигателя расход топлива составляет 0,6 л/4, то сразу же после пуска холодного двигателя при температуре окружающего воздуха $-15^{\circ} \mathrm{C}$ расход топлива при тех же оборотах холостого хода 2,5 л/4, через одну минуту снижается до 1,9 л/4, а через 10 минут работы в режиме прогрева - до 0,8 л/ч. Если же водитель не стал прогревать двигатель, а сразу после пуска начал движение, то расход топлива в начале движения составляет 10 л/100 км, а через 5,5 км движения он снижается до 6,6 л/100 км. 
У автомобиля среднего класса Astra фирмы Opel с дизелем литражом 1,2 л и мощностью 74 кВт при движении с постоянной скоростью при температуре жидкости в системе охлаждения $60^{\circ} \mathrm{C}$ расход топлива составляет 4,3 л/100 км, а при температуре $85^{\circ} \mathrm{C}-3,6$ л/100 км.

Приведённые материалы являются результатами испытаний конкретных автомобилей в конкретных условиях [3]. При аналогичных испытаниях любого другого автомобиля замеряемые величины будут отличаться от приведённых, но общая закономерность не изменится. Прогрев двигателя связан с интенсивным выбросом вредных веществ и повышенным расходом топлива, и чем ниже температура окружающего воздуха, тем выше и вредные выбросы и расходы топлива.

Опыт эксплуатаций автомобилей, на которых установлены бензиновые двигатели с турбонаддувом, показал низкую надёжность турбокомпрессоров. Одной из причин этого является режим прогрева двигателя. Высокая вязкость холодного масла создаёт тормозящий эффект вращению ротора, и турбокомпрессор в этом случае является дополнительным сопротивлением и в системе впуска и в системе выпуска. Если водитель начинает движение при непрогретом двигателе, то нарушаются условия смазки опор вала ротора, что ведёт к повышенному износу пар трения.

Поскольку у бензиновых двигателей температура отработавших газов на $100 \ldots 150^{\circ} \mathrm{C}$ выше, чем у дизелей, специалисты рекомендуют у турбокомпрессоров, устанавливаемых на бензиновые двигатели, делать охлаждение корпуса подшипников жидкостью системы охлаждения двигателя. К сожалению, большинство турбокомпрессоров не имеют такого охлаждения. Введение охлаждения корпуса подшипников целесообразно не только для бензиновых двигателей, но и дизелей. Достоинством дизелей является сохранение максимального крутящего момента на низких частотах вращения коленвала. На этих режимах не всегда можно обеспечить высокий расход масла, не говоря уже о случаях резкого перехода от максимального крутящего момента к минимальным оборотам холостого хода. Поскольку масло является ещё и охлаждающим агентом, температура его в этих случаях может превысить допустимые пределы.

Другим фактором, способствующим низкому ресурсу турбокомпрессора, является недостаточная степень фильтрации масла. На бензиновых двигателях используют масляные фильтры, за- держивающие твёрдые частицы размером более 12...17 мкм. Для подшипников скольжения вала турбокомпрессора, частота вращения которого может достигать 160 тысяч в минуту, требуется более тонкая фильтрация масла.

Все эти приведённые материалы свидетельствуют, насколько важно сократить время прогрева двигателя. Сокращение времени прогрева разными двигателями может быть реализовано разными способами.

Самый эффективный способ - это использование подогревателей-отопителей. Такие подогреватели выпускаются как отдельные агрегаты и предназначены для установки на автомобили. Например, подогреватель-отопитель Hydronic 2 Economy фирмы Eberspacher [4]. Он предназначен для подогрева охлаждающей жидкости в системе охлаждения двигателя и подогрева воздуха в салоне. Он имеет камеру сгорания, свечу накаливания, теплообменник, электронасосы для подачи бензина и для циркуляции жидкости, электровентилятор. Напряжение питания электродвигателей 12 В. Топливо подводится из топливного бака автомобиля. Отработавшие газы отводятся в глушитель. Указанная модель имеет номинальную теплопроизводительность 4 кBт, предусмотрен форсированный режим (4,3 кВт) и режим малой мощности. Расход топлива при работе на форсированном режиме 0,64 л/4, а на режиме малой мощности 0,2 л/ч. Включение и выключение осуществляется посредством радиосигналов от дистанционного пульта управления, который позволяет автоматически включать и задавать продолжительность работы. Имеется специальный разъём для диагностики системы. Вес подогревателя без трубопроводов подвода и отвода 2,4 кг. Выпускается модификация подогревателя, предназначенная для работы на дизельном топливе, то есть для установки на автомобиль с дизелем.

Подогреватели, подобные описанному, выпускаются с разной теплопроизводительностью, и для любого автомобиля можно подобрать соответствующую модель. Известные фирмы, выпускающие подобные подогреватели, - это Calix, DEFA, Webasto, Eberspacher и другие. В подогревателях условия воспламенения и сгорания топлива обеспечивают практически полное отсутствие в продуктах горения вредных веществ.

Вопрос установки на автомобили предпусковых подогревателей не является дискуссионным и автомобили премиум-класса давно оснащены ими, и основное внимание при этом уделяется 
прогреву салона, сидений, стёкол. Но на основной массе автомобилей малого и среднего класса их нет. В конце 2013 года АВТОВАЗ стал выпускать опцию автомобиля Приора с подогревателем фирмы Eberspacher (характеристики одной из моделей этой фирмы приведены выше). Обычно, когда дилеры устанавливают подогреватели на автомобили как дополнительное устройство, возникают проблемы гарантии, надёжности, пожароопасности и другие. В этом случае была заводская установка, но данная опция автомобиля плохо продавалась, и её перестали выпускать. Потребителей отпугивала повышенная цена.

На сегодняшний день основным направлением для недорогих машин является дистанционный пуск двигателя. С 2015 года фирма Renault стала оснащать свои автомобили системой Renault Start, то есть система входит в заводскую комплектацию и имеет гарантию. Система позволяет дистанционно запускать двигатель, который будет работать 10 мин, затем остановится. Предусмотрен режим до 5 пусков двигателя с интервалом 2 часа.

АВТОВАЗ с 2020 года предполагает выпускать автомобили с системой Lada Connect, которая кроме дистанционного пуска позволяет контролировать ряд параметров. Многие зарубежные фирмы уже внедрили подобные системы. Но дистанционный пуск не является решением проблемы. Сегодня концентрация автомобилей в городах такова, что загазованность атмосферы очень высока.

Вследствие высокой конкуренции производители привлекают покупателей созданием удобств. Конечно, дистанционный пуск создаёт удобства водителю. Ему не нужно прогревать двигатель, не нужно счищать лёд со стёкол. Он садится в теплый салон, запускает двигатель и едет. А сколько токсичных газов было выброшено в окружающую среду за время прогрева двигателя - об этом вообще нигде не упоминается. В системe Renault Start, как уже упоминалось, в режиме морозная ночь - двигатель 5 раз с интервалом в 2 часа запускался и прогревался работой на холостом ходу по 10 мин. Прогрев двигателя за счёт работы на холостом ходу не является оптимальным вариантом.

Подогреватели предназначены для эксплуатации автомобилей в зимний период. Но опыт эксплуатации показывает, что даже при температуре окружающего воздуха $+25 \ldots+30^{\circ} \mathrm{C}$, если после длительной стоянки запускается двигатель, то повышенные выбросы вредных веществ и повышенный расход топлива при прогреве будут до тех пор, пока температура охлаждающей жидкости не поднимется до $85 . . .90^{\circ} \mathrm{C}$. Чем ниже температура окружающего воздуха, тем больше время прогрева и больше суммарный выброс в атмосферу вредных веществ.

В летний период в середине дня температура окружающего воздуха может быть $+25^{\circ} \mathrm{C}$ и выше, но ранним утром даже в самые тёплые дни лета температура воздуха $+10 \ldots+12^{\circ} \mathrm{C}$, а может быть и $+5 \ldots+7^{\circ} \mathrm{C}$. Именно ранним утром большинство водителей запускают двигатели своих автомобилей, прогревают их и едут на работу. А поскольку автомобили стоят во дворах и вокруг жилых зданий, жители этих домов, особенно нижних этажей, ощущают повышенную загазованность воздуха. В зимний период эти проблемы значительно обостряются. Поэтому предварительный прогрев двигателя подогревателем является обязательным в любое время года.

Как уже отмечалось, при пуске высокая вязкость масла создаёт проблемы с повышенным расходом топлива и препятствует повышению частоты вращения коленвала вследствие ограниченного поступления масла к парам трения. Поэтому при предварительном прогреве двигателя подогревателем необходимо предусмотреть и прогрев масла. Для этого в поддон нужно установить теплообменник, который будет включён в малый круг системы охлаждения.

Удельная теплоёмкость масла примерно в 1,8 раза меньше, чем у антифриза 40 , а теплопроводность меньше почти в 4 раза. Высокая вязкость масла является причиной того, что в процессе теплообмена между антифризом и маслом конвективная составляющая минимальная. Поэтому прогрев масла в поддоне при неработающем двигателе требует специального теплообменника. При работе подогревателя одновременно будет нагреваться и охлаждающая жидкость и масло в поддоне.

При использовании подогревателя появляется возможность одновременно с прогревом жидкости системы охлаждения подогревать каталитический нейтрализатор, который, как было отмечено выше, начинает работать, когда температура отработавших газов превысит $250 \ldots 300^{\circ} \mathrm{C}$. Продукты сгорания из камеры подогревателя нужно направлять в выпускной коллектор двигателя перед нейтрализатором. Это позволит существенно снизить выбросы СН и СО в первые минуты работы двигателя после запуска, когда эти выбросы имеют максимальное значение. 
Таким образом, все выпускаемые автомобили рекомендуется укомплектовывать подогревателями и теплообменниками масла в поддоне. Операция предварительного прогрева двигателя перед его пуском должна быть обязательна. Требования по уровню предварительного прогрева двигателя перед пуском должны быть введены в стандарты.

С целью облегчения холодного пуска двигателей разработаны и выпускаются различными предприятиями Российской Федерации аккумуляторы тепла (АТ) [5], в комплектность которых входит ёмкость, электронасос с питанием 12 В, узлы управления и детали, позволяющие подсоединить АТ к системе охлаждения двигателя. Высокая степень теплоизоляции ёмкости позволяет сохранить температуру жидкости в течение длительного времени после остановки двигателя. Эффективность АТ будет зависеть от объёма ёмкости и температуры жидкости в ней. Эффективность также будет зависеть от возможности замены в ёмкости горячей жидкости на холодную из системы охлаждения без их перемешивания.

На рисунке 1 построены расчётные зависимости повышения температуры жидкости в системе охлаждения двигателя от объёма ёмкости AT. Объём $V_{\text {Ат }}$ принят в процентах от объёма системы охлаждения $\mathrm{V}_{\text {со' }}$ которая рассматривается без учёта объёмов радиатора и отопителя сало- на, которые в этом случае должны быть отключены. Температура жидкости в ёмкости АТ принята $80^{\circ} \mathrm{C}$. Расчёты сделаны при условии, что горячая жидкость полностью перекачивается в систему охлаждения двигателя, и ёмкость заполняется жидкостью без какого-либо перемешивания. 3ависимости рассчитаны для разных значений температуры жидкости в системе охлаждения от -20 до $+60^{\circ} \mathrm{C}$.

Зависимости показывают, что заметный эффект в прогреве жидкости будет при ёмкости АТ $30 . . .50 \%$ от ёмкости системы охлаждения, не менее. Например, ёмкость системы охлаждения двигателя 8 литров. Оценим эффективность при ёмкости АТ 50\%, то есть 4 литра. После длительной стоянки при температуре окружающего воздуха $20^{\circ} \mathrm{C}$, когда все детали двигателя также будут иметь температуру $20^{\circ} \mathrm{C}$, перед пуском двигателя включим электронасос и перекачаем горячую жидкость из АТ в систему охлаждения, а ёмкость АТ заполнится холодной жидкостью. Температура жидкости в двигателе поднимется на $30^{\circ} \mathrm{C}$ и станет $20+30=50^{\circ} \mathrm{C}$, то есть в систему охлаждения будет введено количество тепла:

$$
\mathrm{Q}=\mathrm{m} \cdot \mathrm{c} \cdot\left(\mathrm{t}_{2}-\mathrm{t}_{1}\right),
$$

где $\mathrm{m}$ - масса жидкости системы охлаждения, кг; с - удельная теплоёмкость антифриза 40, кДж/кг·град;

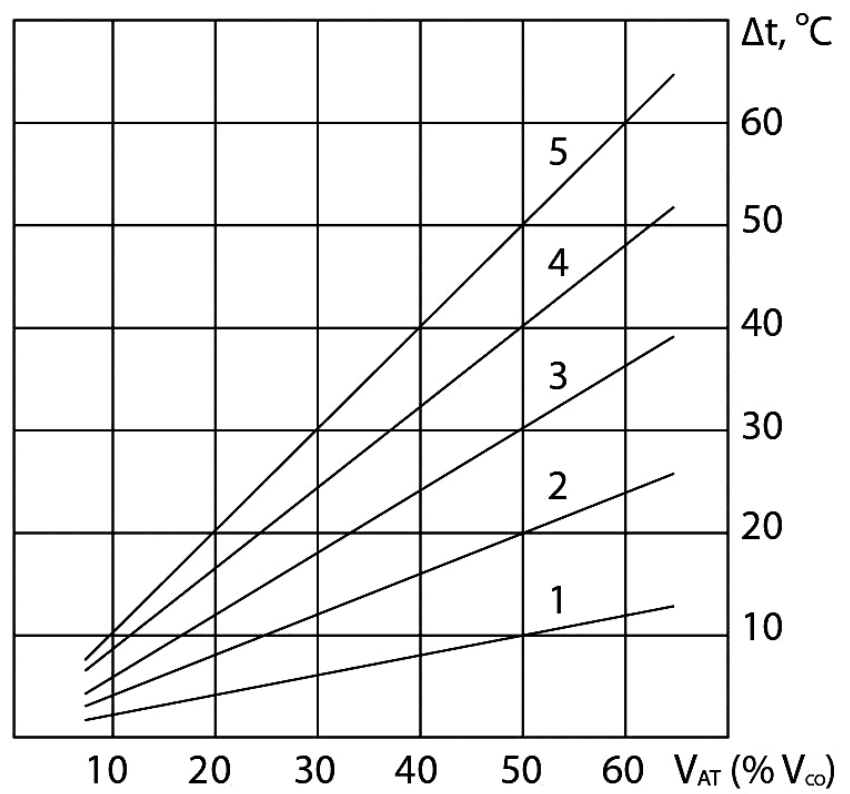

$$
1-\mathrm{t}=60^{\circ} \mathrm{C} ; 2-\mathrm{t}=40^{\circ} \mathrm{C} ; 3-\mathrm{t}=20^{\circ} \mathrm{C} ; 4-\mathrm{t}=0^{\circ} \mathrm{C} ; 5-\mathrm{t}=-20^{\circ} \mathrm{C} .
$$

Рисунок 1 - Повышение температуры охлаждающей жидкости $(\Delta \mathrm{t})$ в системе охлаждения в зависимости от объёма аккумулятора тепла для разных исходных температур жидкости (t) 
$\mathrm{t}_{1}$ и $\mathrm{t}_{2}$ - температуры жидкости до и после перекачивания, ${ }^{\circ} \mathrm{C}$.

Антифриз 40 содержит этиленгликоля по массе $52 \%$. Удельная теплоёмкость при $20^{\circ} \mathrm{C}$ этиленгликоля 2,4, а воды - 4,183 кДж/кг·град. Плотность при $20^{\circ} \mathrm{C}$ этиленгликоля 1,113, а воды - 0,992 кг/л. Поэтому можем принять удельную теплоёмкость антифриза 40 с = 3,3 кДж/кг·град. Количество тепла, введённое в систему охлаждения, составит 792 кДж. Если же температура окружающего воздуха будет $0^{\circ} \mathrm{C}$, то в этом случае температура в системе охлаждения поднимется до $40^{\circ} \mathrm{C}$, то есть в систему охлаждения будет введено 1056 кДж тепла. Эти цифры показывают, что АТ может существенно сократить время прогрева двигателя.

Конечно, указанные температуры жидкости в системе охлаждения будут ниже расчётных, поскольку с поступлением горячей жидкости из АТ одновременно будут нагреваться головка цилиндров и верхняя часть блока. Поэтому для более объективной оценки эффективности АТ необходимо учитывать количество вводимого тепла.

Подогреватели-отопители работают в установившемся режиме с КПД около 50\%. В начальный период, после включения подогревателя, много тепла затрачивается на нагрев самого подогревателя. Приняв КПД подогревателя на этом режиме 25\%, получим, что для введения тепла в охлаждающую жидкость 792 и 1056 кДж потребуется сжечь 72 и 100 г бензина соответственно.

Расчёты количества подводимого тепла сделаны для АТ, имеющего 50\% объёма системы охлаждения. При увеличении ёмкости эффективность АТ будет расти. Но для легковых автомобилей целесообразно использовать ёмкость АТ около 50\%, не более.

АТ не может быть основным источником тепла при предпусковом прогреве двигателя. Он может эффективно использоваться, когда автомобиль работает в условиях, для которых характерны частые остановки. Даже при самой эффективной теплоизоляции ёмкости через 24 часа стоянки автомобиля при температуре окружающего воздуха $20^{\circ} \mathrm{C}$, температура жидкости в АТ будет не более $65 . .70^{\circ} \mathrm{C}$, поэтому пуск двигателя после длительной стоянки должен осуществляться только после прогрева подогревателем, а при остановках на 2-3 часа зимой, а летом и на 6-8 часов, эффективным окажется АТ. Целесообразность установки на автомобиль АТ определяется также тем, что время для перекачки жидкости из АТ в систему охлаждения может составить не более 10-15 секунд.
На рисунке 2 приведена рекомендуемая схема системы охлаждения. Помимо общепринятых элементов системы охлаждения, таких как радиатор, термостат, расширительный бачок, радиатор обогрева салона, рекомендуемая схема включает:

- водяной насос, приводимый во вращение электродвигателем с регулируемой частотой вращения;

- подогреватель;

- аккумулятор тепла;

- теплообменник для подогрева масла в поддоне.

Схема предусматривает только вопросы решения проблемы предпускового прогрева. Про-

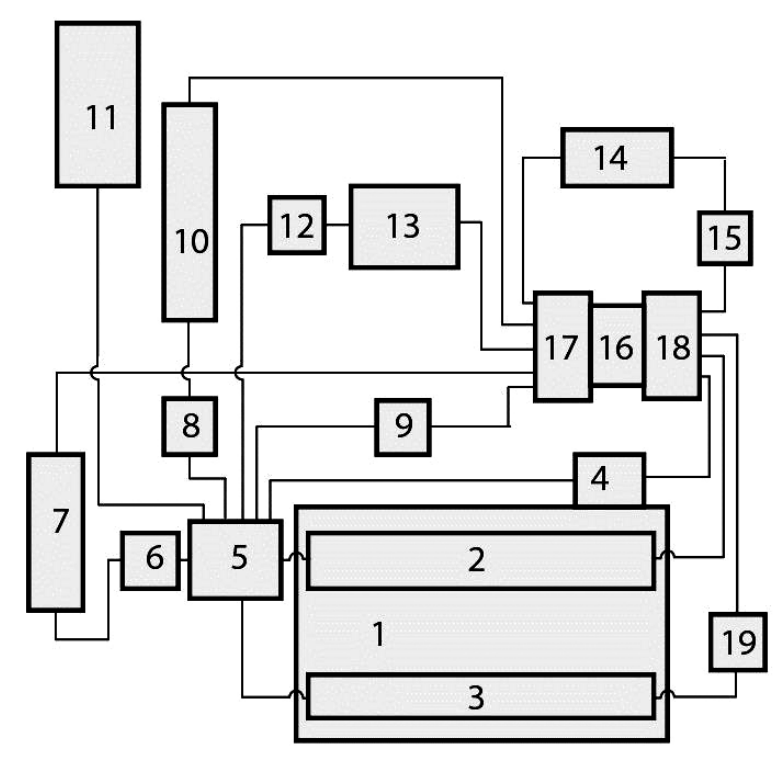

1 - ДВС; 2 - полость охлаждения двигателя;

3 - теплообменник подогрева масла в поддоне; 4 турбокомпрессор; 5 - зона выхода жидкости из полости охлаждения; 6 - термостат;

7 - радиатор системы охлаждения

с электроприводом вентилятора;

8, 9, 12, 19 - электромагнитные клапаны;

10 - аккумулятор тепла; 11 - расширительный бачок;

13 - предпусковой подогреватель; 14 - отопитель

салона; 15 - узел регулирования расхода

жидкости через отопитель салона;

16 - жидкостной насос с электроприводом;

17 - зона всасывания насоса;

18 - зона нагнетания насоса.

Рисунок 2 - Рекомендуемая схема системы охлаждения легкового автомобиля 
блемы обеспечения стабильности теплового режима в разных условиях эксплуатации требуют целого комплекса дополнительных устройств и систем и должны рассматриваться отдельно.

Как уже отмечалось, подогреватели выпускаются как отдельные агрегаты, которые могут по желанию владельца устанавливаться на автомобили для подогрева жидкости системы охлаждения в зимний период. Рекомендуемый нами подогреватель является обязательной комплектностью автомобиля. Он включает камеру сгорания, теплообменник, систему зажигания, топливный насос с электроприводом, электровентилятор, систему программного управления. Циркуляция охлаждающей жидкости через теплообменник подогревателя и систему охлаждения двигателя осуществляется электронасосом двигателя. Продукты горения направляются в выпускной коллектор и обогревают нейтрализатор. Электромагнитный клапан при включении подогревателя соединяет теплообменник подогревателя с системой охлаждения двигателя, а после прекращения работы отключает его. В процессе работы подогревателя прогреваются жидкость системы охлаждения и масло в поддоне, а также корпус подшипников турбокомпрессора и нейтрализатор. Поэтому время прогрева двигателя после пуска будет минимальным. Это позволит снизить выбросы вредных веществ, снизить расход топлива, уменьшить вероятность появления дефектов вкладышей коленвала, подшипников турбокомпрессора.

При предпусковом цикле работы подогревателя, учитывая соотношения количества и теплоёмкости жидкости в системе охлаждения и масла в поддоне, 75...80\% горячей жидкости из теплообменника-подогревателя должно поступать в охлаждающую полость, а $20 . .25 \%$ - в теплообменник для подогрева масла. Если в процессе работы двигателя температура масла в поддоне превысит допустимое значение, электромагнитный клапан 19 откроет проход, и охлаждающая жидкость начнёт поступать в теплообменник до тех пор, пока температура масла не снизится до установленной величины.

Производители автомобилей должны самостоятельно решать вопросы выбора типа и мощности подогревателей, конструкции и места расположения аккумулятора тепла, конструкцию и характеристики подогревателя масла в поддоне. Что касается AT, то верхняя точка ёмкости должна быть ниже уровня жидкости в расширительном бачке. В зависимости от разности температур жидкости в АТ и в системе охлаждения перед пуском двигателя, в соответствии с программой, электромагнитный клапан соединит системы и электронасос, за несколько секунд перекачает жидкость из АТ в систему охлаждения, причём часть горячей жидкости будет поступать в полость охлаждения, а часть - в теплообменник в поддоне двигателя. Заполнение АТ горячей жидкостью будет происходить на рабочих режимах после сравнения температуры в системах.

Электропривод насоса охлаждающей жидкости позволяет существенно повысить степень оптимизации и автоматизации процессов охлаждения. Современные достижения в области электротехнологий обеспечивают возможность изменения частоты вращения вала электродвигателя в широком диапазоне за счёт, например, широтно-импульсной модуляции.

Электропривод насоса даёт возможность использования и подогревателя, и АТ при неработающем двигателе. Ценным также является возможность регулирования производительности насоса в зависимости от работы двигателя. Например, при движении автомобиля на затяжных подъёмах электронасос может работать при максимальной производительности, а после внезапной остановки двигателя он может продолжать работать, чтобы исключить местный перегрев головки цилиндров, цилиндропоршневой группы, корпуса подшипников турбокомпрессора. При работе двигателя на любых режимах за счёт изменения производительности насоса можно будет поддерживать оптимальные значения температур поверхностей, определяющих полноту сгорания топлива в камере сгорания. Немаловажным достоинством является расположение насоса в любом месте, оптимальном с точки зрения снижения гидравлических сопротивлений, удобства монтажа трубопроводов и обслуживания системы.

В связи с усложнением системы охлаждения встаёт вопрос о стабильности расходов через разные теплообменники. В работе [6] рекомендуется на автомобилях использовать объёмные делители расходов. Такие устройства используют в сложных гидросистемах, когда требуется обеспечить строгую идентичность перемещения нескольких гидроцилиндров. В двигателях легковых автомобилей основной поток охлаждающей жидкости проходит через полость охлаждения, а теплообменники включаются только на короткий период и в основном в режиме предпускового прогрева. Поэтому требуемые расходы 
можно обеспечить подбором дросселирующих сечений.

На рекомендуемой схеме охлаждения выделено три зоны: зона 17 на входе в насос - это зона низкого давления; зона 18 на выходе из насоса, то есть зона высокого давления; и зона 5 на выходе из полости охлаждения перед термостатом. Скорость прохождения основного потока через полость охлаждения определятся перепадом давлений между зонами 18 и 5. Перепад давлений между зонами 5 и 17 при открытом термостате должен обеспечивать требуемый расход жидкости через радиатор системы охлаждения. Для всех трёх зон характерно большое количество подводящих и отводящих трубопроводов. Поэтому желательно эти зоны выполнять как отдельные узлы, обеспечивая удобство монтажа и контроля соединений. Проходные сечения и гидравлическое сопротивление элементов системы охлаждения для конкретного автомобиля должны подбираться опытным путём с учётом места расположения насоса.

При предпусковом прогреве двигателя отопителем необходимо, чтобы весь поток нагнетаемой насосом охлаждающей жидкости проходил через теплообменник отопителя. Это обеспечивается установкой электромагнитного клапана 9, который на этом режиме перекроет проходное сечение. То же самое будет происходить при предпусковом прогреве за счёт АТ. После выключения как отопителя, так и АТ, клапан 9 откроет проходное сечение, и система охлаждения будет функционировать в обычном режиме.

Проблемой является размещение дополнительных агрегатов в подкапотном пространстве автомобиля. Но проблема экологии и надёжности двигателей настолько важны, что производители автомобилей обязаны пересмотреть компоновку силового агрегата в автомобиле. Кстати, уже много лет обсуждается вопрос о повышении напряжения питания в легковых автомобилях с 12 до 36, или даже до 48 В. Преимущества такого увеличения намного превышают недостатки. И на некоторых внедорожниках напряжение уже подняли до 48 В. А недостаток - тяжёлая громоздкая батарея или комплект батарей. Располагать их нужно толь- ко в багажнике, и тогда вопросы размещения дополнительных агрегатов будет легче решать.

Реализация предлагаемых изменений может быть осуществлена введением дополнений в стандарты. Стандарты на пусковые качества автомобильных двигателей [7] указывают предельные температуры надёжного пуска и время подготовки двигателя к принятию нагрузки. Причём, для автотранспортных средств народно-хозяйственного назначения по согласованию между предприятием-изготовителем и потребителем допускается не устанавливать систему предпускового подогрева и устройство облегчения пуска холодного двигателя. Дополнения в стандарты должны предусматривать минимальную температуру в системе охлаждения, при которой после прогрева двигателя подогревателем разрешается пуск двигателя. Тогда время подготовки двигателя к принятию нагрузки будет иметь конкретный смысл. Обязательно должно быть оговорено допустимое количество токсичных газов, выбрасываемых в первую минуту работы двигателя после пуска. Причём, допустимое количество должно быть указано для условий пуска как при отрицательных температурах окружающего воздуха, так и положительных. Конкретные рекомендации должны быть приняты после предварительного обсуждения проблемы специалистами ведущих производителей автомобилей.

\section{Выводы}

Предварительный прогрев двигателя подогревателем является обязательным в любое время года. Известно, что работа двигателя легкового автомобиля в режиме прогрева сопровождается интенсивным выбросом в атмосферу вредных веществ и повышенным расходом топлива.

Авторами разработана схема системы охлаждения легкового автомобиля, включающая, помимо общепринятых элементов системы охлаждения, подогреватели-отопители, аккумуляторы тепла и теплообменники для нагрева масла в поддоне. Рекомендуемая система охлаждения позволит сократить время предпускового прогрева двигателя, а соответственно, и количество выбросов вредных веществ.

\section{תumepamypa}

1. Правила ЕЭК ООН №83-04. Требования к выбросам автомобильной техникой вредных веществ.

2. Азаров, В.К. Проблемы создания экологически чистого автомобиля [Текст] / В.К. Азаров, В.Ф. Кутенёв, А.М. Сайкин // Автомобильная промышленность. - 2013. - № 10. - С. 5-7.

3. Вредные выбросы и подогрев двигателя [Электронный ресурс]. - Режим доступа: https: https://tech. wikireading.ru/13634 (дата обращения: 01.11.2018). 
4. Володин, В. Компактные обогреватели-отопители для легковых автомобилей. [Текст] / В. Володин // Автомобилестроение за рубежом. - 2012. - № 4. - С. 21.

5. Предпусковой подогреватель МАДИ УОПД [Электронный ресурс]. - Режим доступа: http://catalog. autodela.ru/good/view/873 (дата обращения: 01.10.2018).

6. Карелин, Д.Л. Многоконтурные системы охлаждения на основе объемного делителя потока [Текст] / Д.Л. Карелин, В.М. Гуреев, В.Л. Мулюкин // Автомобильная промышленность. - 2014. - № 5. - С. 13-15.

7. ГОСТ Р 54120-2010. Двигатели автомобильные. Пусковые качества. Технические требования [Электронный ресурс]. - Режим доступа: http://docs.cntd.ru/document/gost-r-54120-2010.

\section{References}

1. Pravila EJeK OON №83-04. Trebovanija k vybrosam avtomobil'noj tehnikoj vrednyh veshhestv.

2. Azarov, V.K. Problemy sozdanija jekologicheski chistogo avtomobilja [Tekst] / V.K. Azarov, V.F. Kutenev, A.M. Sajkin // Avtomobil'naja promyshlennost'. - 2013. - № 10. -S. 5-7.

3. Vrednye vybrosy i podogrev dvigatelja [Jelektronnyj resurs]. - Rezhim dostupa: https: https://tech. wikireading.ru/13634 (data obrashhenija: 1.11.2018).

4. Volodin, V. Kompaktnye obogrevateli-otopiteli dlja legkovyh avtomobilej. [Tekst] / V. Volodin // Avtomobilestroenie za rubezhom. - 2012. - № 4. - S. 21.

5. Predpuskovoj podogrevatel'MADI UOPD [Jelektronnyj resurs]. - Rezhim dostupa: http://catalog.autodela. $\mathrm{ru} / \mathrm{good} / \mathrm{view} / 873$ (data obrashhenija: 1.10.2018).

6. Karelin, D.L. Mnogokonturnye sistemy ohlazhdenija na osnove ob\#emnogo delitelja potoka [Tekst] / D.L. Karelin, V.M. Gureev, V.L. Mulyukin // Avtomobil'naja promyshlennost'. - 2014. - № 5. - S. 13-15.

7. GOST R 54120-2010. Dvigateli avtomobil'nye. Puskovye kachestva. Tehnicheskie trebovanija [Jelektronnyj resurs]. - Rezhim dostupa: http://docs.cntd.ru/document/gost-r-54120-2010.

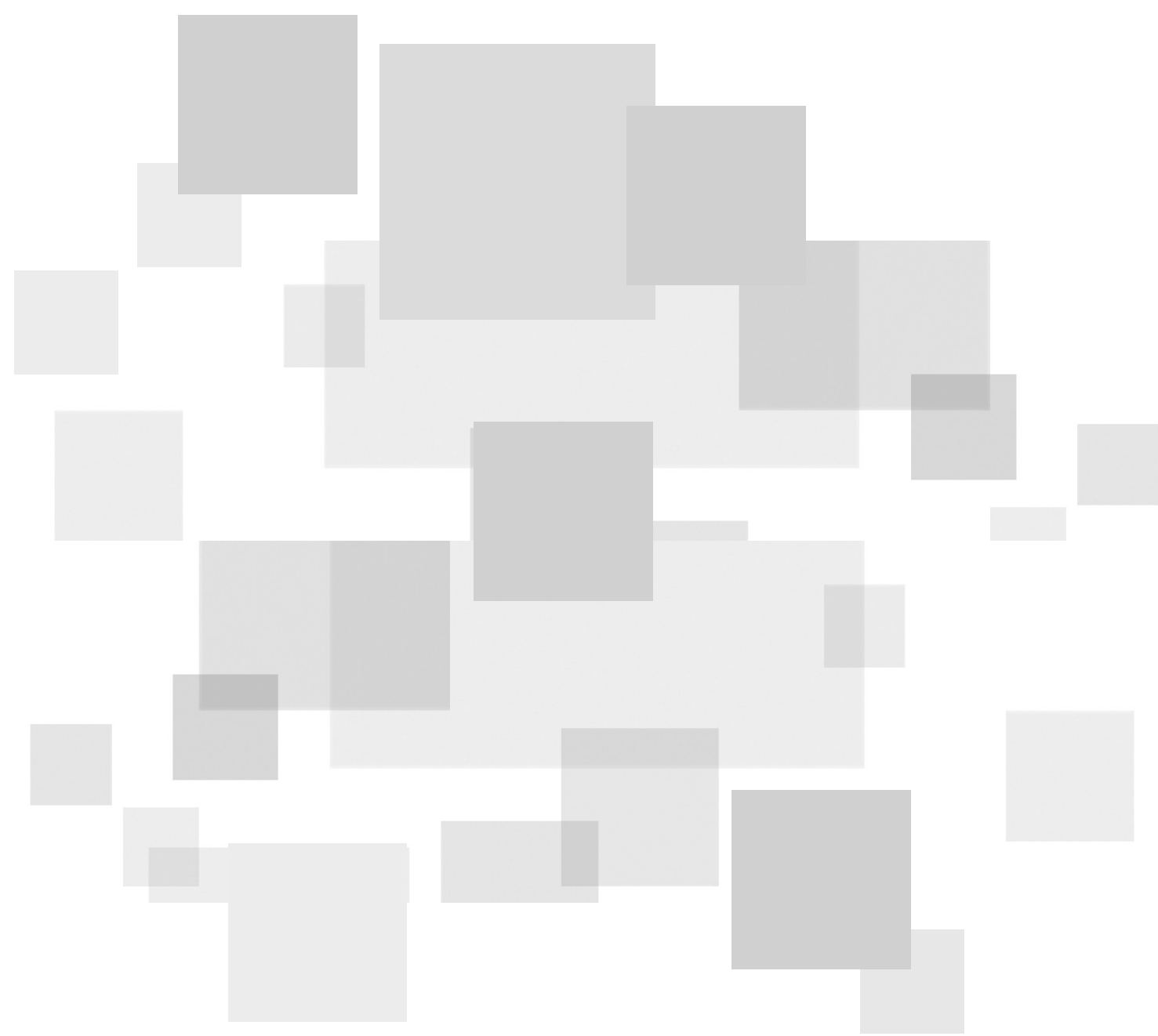

